\title{
A Hybrid Multi-Agent/Spatial Interaction Model System for Petrol Price Setting
}

\author{
A.J. Heppenstall, A.J. Evans and M.H. Birkin \\ School of Geography, University of Leeds \\ Woodhouse Lane, Leeds, LS2 9JT \\ Telephone: $+44(0) 1133436639$ \\ Fax: +44 (0)1133433308 \\ Email: a.heppenstall@geog.leeds.ac.uk
}

\begin{abstract}
This paper outlines the findings of ongoing research on the application of multi-agent simulations (MAS) to modelling complex locally interacting dynamic systems, in particular the petrol price market. The development of an agent based model for petrol prices is presented. Failings within this model are discussed and an alternative strategy for controlling the price of each petrol station based on profit maximisation is considered. A spatial interaction model was used to estimate the sales and linked to the agent system to create a hybrid model. To evaluate how effective this hybrid model was, a comparison was made with an existing data set of real petrol prices collected over a two month period. This was achieved both statistically and visually with the use of a Geographical Information System (GIS). Experimentation revealed that the hybrid model outperformed the agent model. Investigation into the behaviour of the system (how prices diffuse spatially) was undertaken by means of idealised simulations.
\end{abstract}

\section{Introduction}

Petrol is one of the most valuable oil derived commodities, valued by retailers and customers alike. Despite pressures on natural resources there is a rising demand for petrol associated with an ever increasing individual mobility. At the end of 2002, there were 11,707 sites retailing over 36 billion litres of motor fuel in the UK. This equates to an average of approximately 1,350 litres of fuel consumed by each vehicle per annum. Consumers are becoming ever more aware of petrol prices; internet sites such as the AA Price Watch enables the consumer to have almost perfect knowledge of prices within their area. This has created both a highly competitive and sensitive market, with organisations employing strategies to maximise profits. This sensitivity to petrol prices was fully borne out in the UK during August - September 2000 with the "Petrol Crisis" and the associated fuel protests that precipitated in reaction to soaring fuel taxes.

The literature concerned with the examination of petrol prices and its relationship with other variables is vast. Concentration is mainly focused on the transmission of positive and negative changes in a variable in relation to the price of petrol (for example, crude oil prices or exchange rates). These studies generally differ in one or more of the following aspects; the country under scrutiny; the time frequency and period of data used; the focus on wholesale and retail gas prices or oil and petrol 
prices and finally the dynamic model employed in the empirical investigation (Galoetti et al. 2003). Examples of work within this area include Bacon (1991), Manning (1991), Shin (1994), Reilly \& Witt (1998) and Mitchell et al. (2000). High frequency cycles (whether there is a weekly or monthly variation within petrol prices) are another area that occupies substantial amounts of the literature. These have been thoroughly investigated and re-investigated by Castanias \& Johnson (1993), Noel (2002) and Eckert (2002, 2003).

Typically, the models developed by researchers to represent the relationship between petrol and a variable are empirically based, set up with mathematical relationships between variables. Despite numerous advances made in theory and practice (Pave, 1994), these models do present certain problems. For example, mathematical models link up parameters that are all on the same scale of analysis. It is not possible to make the behaviours executed at the 'micro' level correspond with the global variables measured at the 'global' level. The equations that are used are generally complex, containing large numbers of parameters that are both difficult to estimate and lacking realism. Very little, if any, account of any geographical effects are taken. One of the largest criticisms of mathematical models is that it is difficult to take into account the actions of individuals and therefore the modifications to the environment which result from their behaviour. As Ferber (1999) highlights, "If we consider actions only in terms of their measurable consequences at the global level, or of their probability of appearance, it will be difficult to explain phenomena emerging from the interaction of these individual behaviours, in particular all those relating to intra- and interspecific cooperation". The final criticism that can be addressed at these models is that by their nature, mathematical models only consider quantitative parameters. Vast amounts of valuable information can be input to a model by use of qualitative data.

The research presented here differs from previous studies in several ways. Firstly, the technique employed is not empirically based; it is taken from the field of artificial intelligence (AI). Instead of aiming to examine relationships between variables, it aims to model the behaviour of individual petrol stations, the rules that they employ and strategies implemented. Within this paper, we present a hybrid-multi-agent model that seeks to represent the rules and patterns governing real petrol markets by the use of self-interested agents that are fed important system behaviour by a spatial interaction model. The behaviour of the system is further tested by use of idealised simulations. This will be used to specifically examine the spatial diffusion of price changes within the system. Finally, the hypothesis that local optimisation of profit leads to region-wide increase in the market profits is examined.

\section{Agent-Based Systems}

Agent systems are a relatively new paradigm for developing software applications. Their vast potential in designing and building complex systems (Jennings, 2000) coupled with the increase in computing power and the advantages that they offer over traditional approaches has resulted in agent-based models becoming an increasingly popular and powerful tool within geographical applications (O'Sullivan, 2000). There is no universally agreed definition of an intelligent agent (see Franklin 1996, for further discussion) with researchers continually debating whether definition should be by an agents' application or environment (Goodwin, 1993; Brenner 1998). With an 
ever-increasing list of agents appearing (Nwana, 1996), the most useful characterisation comes from Wooldridge (1997):

"An agent is an encapsulated computer system that is situated in some environment and that is capable of flexible, autonomous action in that environment in order to meet its design objectives".

Applications of agents can be found in many areas from electronic commerce, the gaming industry through to industrial applications. Examples of agent models currently within the geographical domain are SprawlSim (designed to help public planners experiment with ideas about suburban sprawl); STREETS and SWARM (both modelling pedestrian movement within public areas) and TRANSIM (a tool for simulating traffic levels). These applications readily exploit the ease of decomposition allowing several processes to be modelled at different temporal and spatial scales.

\subsection{Petrol Stations as Agents}

The petrol pricing market can be viewed as a complex system. Many processes combine at different temporal and spatial scales to affect the overall petrol price. For example, internal costs (cost of production, fixed costs e.g. staff pay), external influences (price of crude oil and levels of taxation) and effects of locality. More importantly, it is hypothesised that competition within the local neighbourhood exerts the greatest influence on setting of price. For example, it is well publicised that ESSO operate a "PriceWatch" policy that aims to match all prices within $3 \mathrm{~km}$.

Agent-orientated approaches advocate decomposition of the problem to be solved. This results in multiple agents being able to engage in flexible, highly-detailed interactions. This decomposition offers two main advantages in modelling complex systems. Firstly, the amount of system control is reduced which results in a lower degree of coupling between components. Secondly, decisions about actions to be performed are devolved to autonomous entities based on the agent's state of affairs rather than an external entity's perception of this state (Jennings, 2000). This approach is well suited to geographical applications, such as the petrol pricing market, where there are a discrete set of spatially distributed entities, in this case petrol stations, that interact with each other and their environment.

A simple agent model was developed with an object-orientated language (Java). Individual petrol stations were created as objects and supplied with knowledge of their own price and sales and the price of those stations within their neighbourhood. Each petrol agent can be characterised as being heterogeneous, possessing a fixed location and a petrol price and separate rule sets to differentiate them; communicative and cooperative with pricing information shared between the agents for competition and reactive, making decisions and changing their prices based on information supplied to them. Diagrammatically, a set of petrol agents within the system may be represented as: 




Figure 1: A set of petrol agents (following the style of Tsvetovat and Carley, 2002)

The mechanism that an individual agent operates is:



Figure 2: Pseudo code representing the mechanism of the petrol agent.

\subsection{Decision Making}

The price of petrol that a station sells is decided via a set of rules. These rules can be assigned to either a group of stations, for example the ESSO brand, all the stations contained within an area, or to all the stations. They are based on industry knowledge and implemented after experimentation with differing parameters. The parameters that form the basis of the rules and an example rule used by a petrol agent are:

- Minimum and maximum price.

- Undercutting price. 
- Overprice (the amount by which a petrol station can be more expensive than its neighbours)

- Neighbourhood.

\section{Example:}

- Am I more expensive by $\mathrm{Xp}$ than the competition in my neighbourhood (Ykm)? If yes, drop my price by Xp.

Interplay of different rules sets allow the stations to be competitive and implement behaviour (e.g. price cutting wars) that leads to profit maximisation. The stations update their prices once per day after a decision has been made. Although one of the advantages of using a MAS is the allowance of asynchronous behaviour, the petrol market simulation is based on a synchronous response, i.e. petrol stations are hypothesised to update their prices once per day in response to corporate instructions or reaction to local competition.

\subsection{Self-interest}

The petrol agents within the system are designed to be self-interested. In making a decision (deciding what price to set), the agents are only concerned with their own immediate profit. This profit maximising behaviour can be seen as a dominant strategy thereby driving out all secondary ones (e.g. attaining market share, collusion for market saturation). It is possible that these behaviours are in fact the dominant or at least equally influential within the system. This paper will concentrate on using the profit maximisation strategy. Further research will investigate the other strategies outlined.

\section{Analysis Tools}

The data is characterised by being both spatially and temporally dynamic. Assessment of the results has to take these characteristics into account. A combination of two methods (statistical and visual) will be used to assess the performance of the agent model. Firstly, the difference between the real and model data at each petrol station will be calculated. This can be achieved by using basic statistical measures such as the mean and standard deviation. To understand patterns and processes over time and within different geographical areas of the study, a method of visualisation needs to be employed. A Geographical Information System (GIS) provides the ability to map changes over an area and add in useful contextual information, e.g. roads. Additionally, interpolation can be achieved within a GIS thus producing price surfaces. Although the result is isotropic, it is a valuable visualisation tool for assessing patterns spatially.

\section{Real Data}

The data set consists of daily petrol price readings taken throughout the months of July, August and September 1999. Geographically, the data set covers the UK and 
many of the main petrol retailers, for example internationals such as ESSO, BP, TEXACO and SHELL; supermarket garages such as Sainsbury's, ASDA, TESCO and Morrisons, and numerous "independents". The prices of the four main petrol types of unleaded, super unleaded, diesel and four star are recorded; in total, there are over 16,000 data points. As every outlet sells unleaded and it is therefore the largest group of data, this will be used within the experiments.

\section{Initial Experiments with an Agent Model of Petrol Pricing}

In the experiments conducted with the agent model, all the petrol stations within two selected areas (West and South Yorkshire) were assigned a list of rules. Initially, all the stations operated the same rules (parameters selected after experimentation). The experiments were initialised with the real data and the simulations were run to equilibrium (defined as the stage when all the prices within the area remained static for 3 days). The measure of success of a simulation was primarily based on the mean and standard deviation. These were calculated by comparing the real and model price at the same petrol station.

Comparison of the agent model with the real data consistently showed that the agent model mirrored the trends within the real data accurately (Figure 3). In terms of price, the agent model did under-predict the prices, a factor that increased over time. However, the agent model only took 2 days (iterations) to reach equilibrium. This is clearly not enough time for the model to operate the rule set. It was therefore concluded that any variations in the difference between the real and model data were actually due to changes within the real data. Additional analysis indicated that the agent model was not accounting for geographical variations (for example, different pricing strategies within rural and urban areas) within the study area and the rules did not make the petrol station strategies competitive enough. The principal aim of a petrol station, as with any business, is to maximise its profit. The rules described so far only look at fuel price rather than the overall profit. The final and perhaps the greatest deficiency in performance was attributed to the lack of consumer behaviour within the model. Essentially, the agents were too "simple", i.e. they did not possess enough knowledge of processes within the system to be able to replicate the patterns.

\section{Spatial Interaction Model}

One of the strategies employed to counter the failure of the agent model was the use of a spatial interaction model. Traditionally, spatial interaction models are used for what-if? scenarios (Birkin et al., 2002). For example, what will happen to the sales of supermarket X if supermarket Y locates nearby? Within this model, they are used to calculate volume of sales information which will be fed to each agent (station). This information will be used to calculate the amount of profit that is being made. 


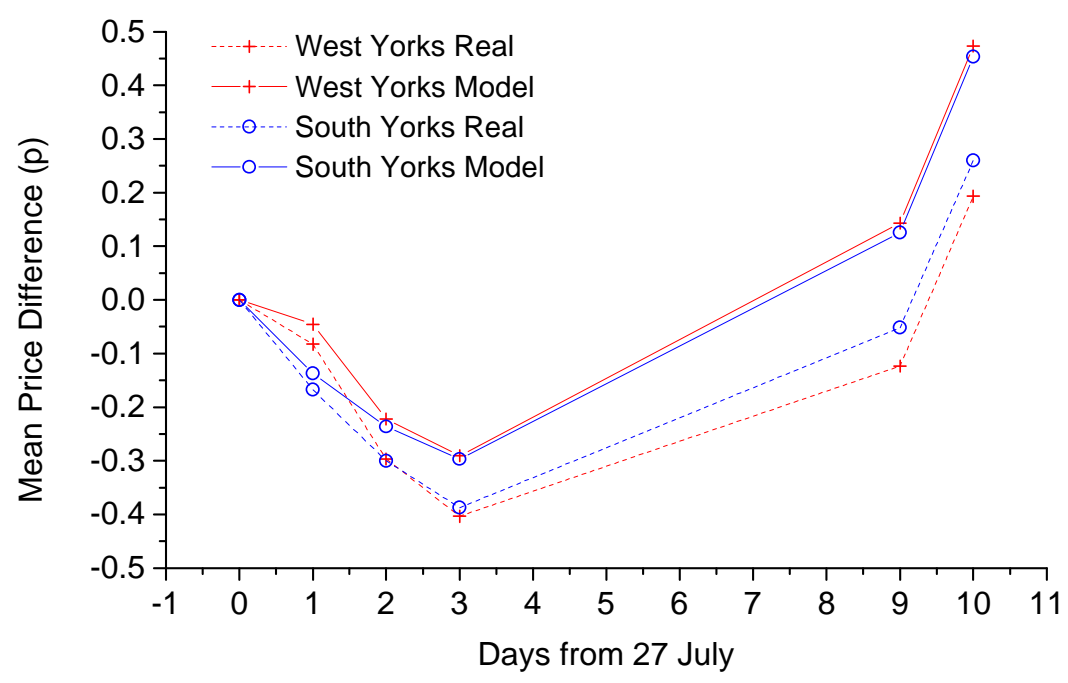

Figure 3: Comparison of the trends of the mean price difference from the starting date within West and South Yorkshire for the agent results and real data.

The petrol station will then implement profit maximising strategies based on this information. The model will be implemented in two stages. Equation (1) calculates the relative amounts of fuel sold by each garage to each UK census ward. The amount sold decays exponentially with distance between the ward centroid and the garage and with price. The exponential function was chosen to give garages closer to the ward centroid a higher attractiveness then petrol stations at a distance. This results in stations which are at a distance and/or selling highly priced petrol having low sales. Equation (2) represents the normalising process to ensure that the total volume of each fuel sold to each ward equals the demand $H_{i} F^{m}$ (the amount of fuel $m$ required by car owners in ward $i$ per day). This gives the actual amount sold in each ward. $\lambda$ and $\beta$ are two coefficients to be determined.

$$
\begin{aligned}
& \hat{S}_{i j}^{m}=\delta_{j}^{m} \exp \left[-\beta d_{i j}-\lambda p_{j}^{m}\right] \\
& S_{i j}^{m}=\frac{\hat{S}_{i j}^{m}}{\sum_{j} \hat{S}_{i j}^{m}} H_{i} F_{m}
\end{aligned}
$$

where:

- $\quad S_{i j}^{m}$ is the amount of fuel $m$ sold by garage $j$ to ward $i$.

- $\delta_{j}^{m}$ is 1 where garage $j$ sells fuel $\mathrm{m}$ and 0 otherwise.

- $\quad d_{i j}$ is the distance between ward $i$ and garage $j$.

- $\quad p_{j}^{m}$ is the price of fuel $m$ at garage $j$.

- $\quad H_{i}$ is the number of households within the ward $i$.

- $\quad F^{m}$ is the amount of fuel of type $m$ required per household per day.

The probability that a consumer will purchase petrol from any of the stations is hypothesised to depend on the price of the petrol in that local sub-market relative to 
the prices charged at the other sites. There are two elements to petrol prices, the cost of the petrol and the transportation costs incurred by the consumer going to the garage. This model assumes that these transport costs are negligible; this can be justified where journeys are short and other purchases are being made. Plummer et al. (1998) hypotheses that this is the case for most petrol sales because they are made in the consumer's immediate neighbourhood during the course of other activities rather than as the results of special trips.

The main driver within the model is profit. All stations are trying to maximise their own profits. To realistically model the behaviour of petrol stations, the following rules were implemented after experimentation:

1. If the profit is increasing then carry on with the current price strategy (i.e. Keep track of the profit and last change of price, don't change anything unless the profit is falling).

2. If the profit is falling, change the strategy to either:

a. Increase the price.

b. Decrease the price.

if either of these improves the situation, then return to step 1.

3. If the profit between the last two iterations hasn't changed much (i.e. It has reached the peak of its profit curve), then keep the price constant until the profit falls again.

To account for this, three equations were built into the model (Equations (3), (4), (5)). The income for garage $j$ from fuel type $m$ is given by

$$
D_{j}^{m}=\sum_{i} S_{i j}^{m} P_{j}^{m}
$$

where

- $\quad D_{j}^{m}$ is the amount of money that garage $j$ takes from fuel $m$.

- $\quad S_{i j}^{m}$ is the amount of fuel bought by ward $I$ from garage $j$.

- $\quad p_{j}^{m}$ is the price of fuel $m$ at garage $j$.

The total cost of production is:

$$
C_{j}^{m}=\sum_{i} S_{i j}^{m} P_{j}^{m}(0)+Q_{j}^{m}
$$

where

- $\quad C_{j}^{m}$ is the amount that it costs the garage $j$ to produce the petrol.

- $\quad P_{j}^{m}(0)$ is the cost per litre to produce and sell fuel $m$ at garage $j$.

- $\quad Q_{j}^{m}$ is the fixed cost to the garage of selling fuel $m$ at garage $j$. This might include for example the cost of staffing the station and maintaining the buildings which do not depend on the amount of fuel sold. 
The profit from fuel $m$ at garage $j$ is then given by:

$$
\Pi_{j}^{m}=\left(D_{j}^{m}-C_{j}^{m}\right)
$$

\subsection{Linking the Agent and Spatial Interaction Model}

The interaction between the agent model and spatial interaction model can be summarised as:

1. The agent model is initialised with the real data (Day 0).

2. Additional data e.g. ward data is read in.

3. The fuel price and station location data is passed to the spatial interaction model.

4. The spatial interaction model calculates fuel sales for each station.

5. The fuel sales are passed to each station. Different garages can use this information in different ways depending on rule assignment.

6. Each agent calculates its new price and the simulation is returned to step 4 until equilibrium or a set time limit is reached.

The interaction between the two models is diagrammatically expressed in Figure 4.

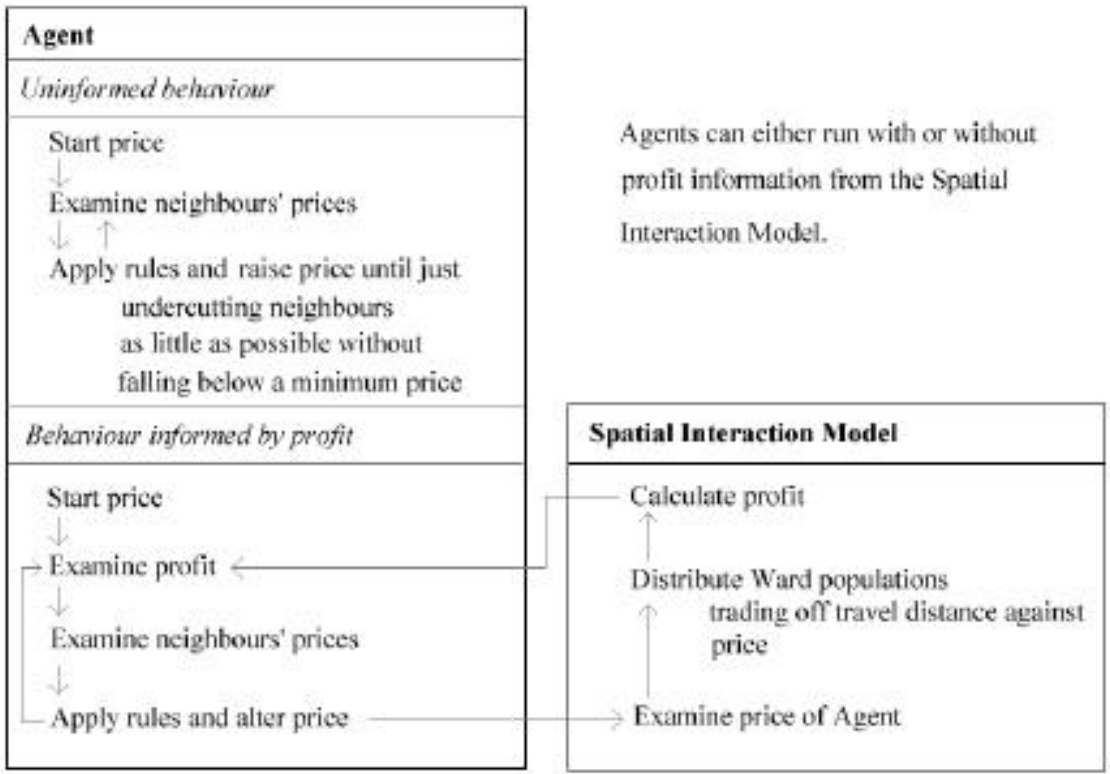

Figure 4: Conceptual representation of the interaction of the agent and spatial interaction model.

\section{Comparison of the Agent and Hybrid Model Performance}

The hybrid model was tested against known data for pump prices in the West Yorkshire area in the months of July and August 1999. The results using strategies based solely on the price of the neighbouring stations (no involvement of the spatial 
interaction model) showed that the agent model was representing some of the processes within the system. The best model performances came from simulations that hit equilibrium rapidly. In these cases, the agent model was not modifying the prices so the results were effectively the same as doing nothing (Figure 5). In reality the primary motivation for a petrol station is the maximisation of profit which these strategies cannot capture. This information on sales (and hence profit) was incorporated by building and attaching a spatial interaction model to the agent model. This hybrid agent model has a sounder theoretical basis (it models real processes), but by solely assessing Figure 5 does not appear to improve on the performance of the agent model. However, this is misleading.

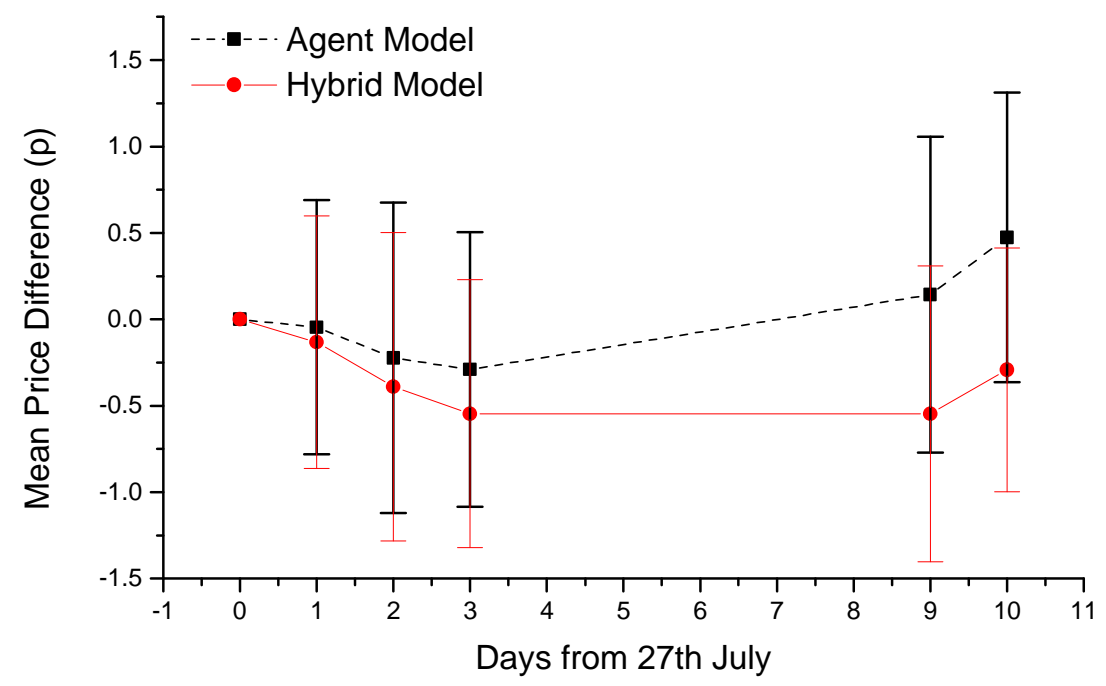

Figure 5: Graph showing the comparison of the trends of the mean price difference from reality for the agent and hybrid model over time.

A better test of the performance of the two models is to assess whether they can reproduce the spatial variations in price observed in the real data. The agent and hybrid model were run with all the petrol stations being assigned the same initial price. The model was allowed to run to equilibrium. No price changes were observed with the agent model (Figure 6a), since the rules used assumed that this was a stable situation. The hybrid model performs much better (Figure 6b), and is beginning to reproduce price variations similar to that observed in the real data (Figure 6c), for example between high priced rural areas and cheaper urban areas. The model still needs to produce a little more price differentiation within the urban areas. This might imply that the rules for rural and urban agents need to be differentiated in future experiments.

\section{Regional Profit Increases from Local Profit Maximisation?}

At the beginning of the paper, it was hypothesised that despite being myopic and selfinterested, the agents, in their quest for higher profits, will produce a market that increases profit on a regional scale. With the development of the hybrid model, we 

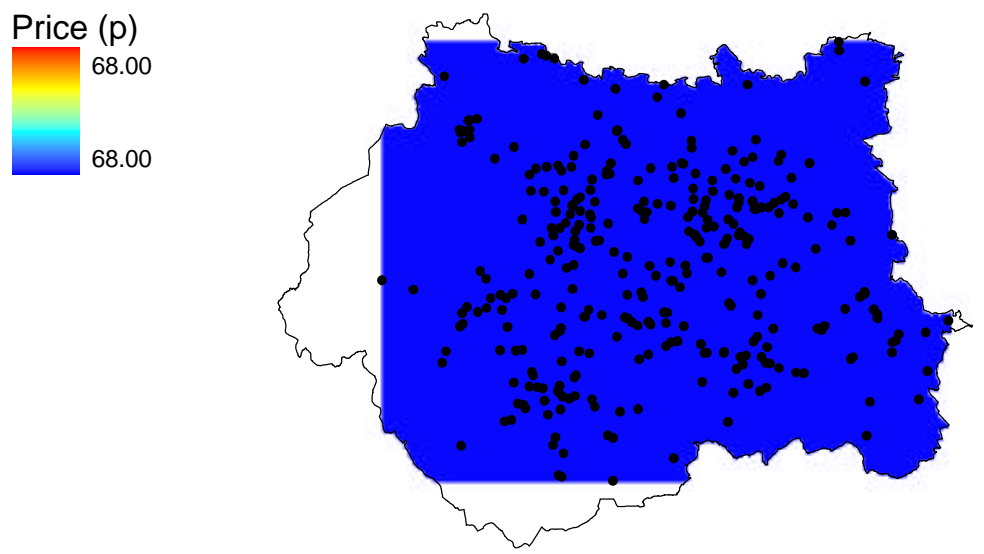

Price (p)

(a) Agent Model
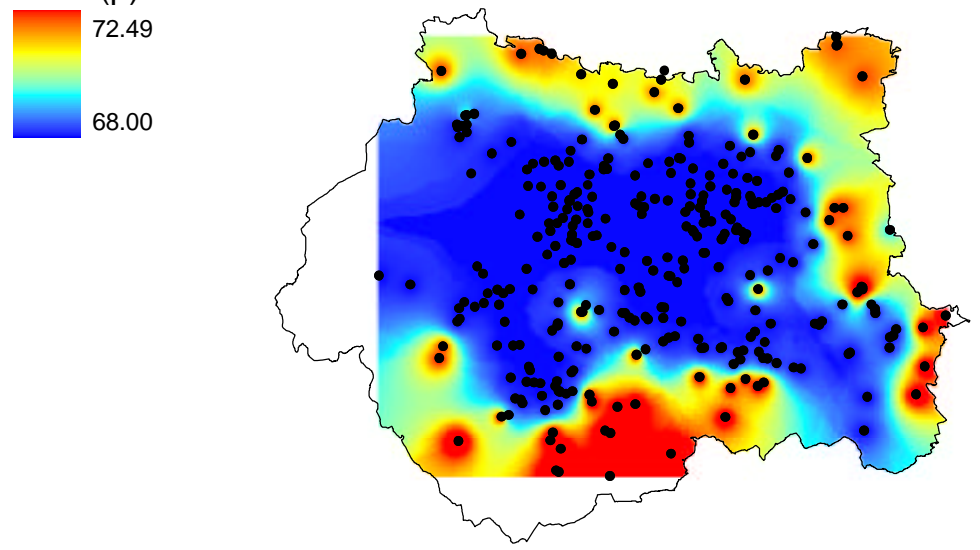

(b) Hybrid Model
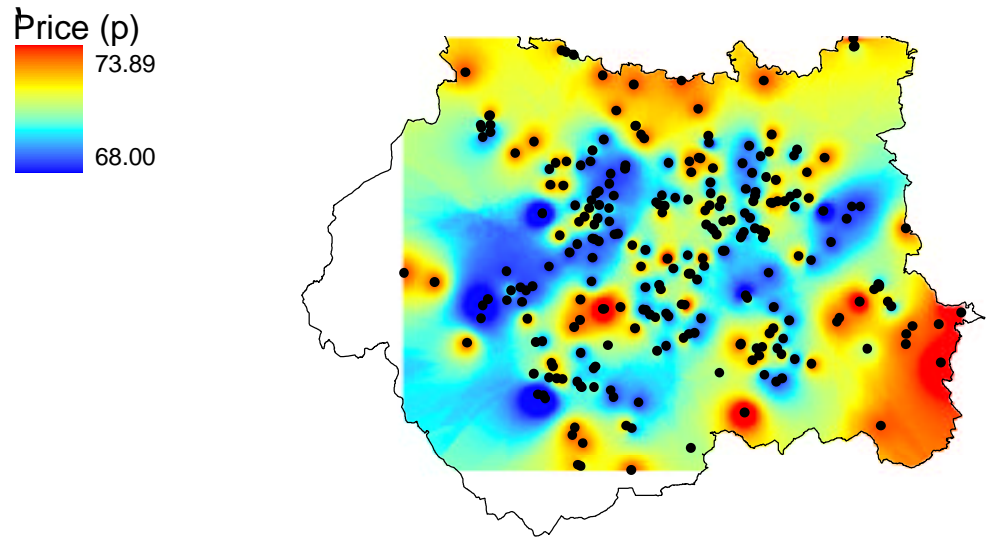

(c) Real Data

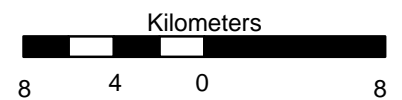

Figure 6: Interpolated price surface maps showing the final equilibrium state of the agent model (a), hybrid model (b) and the real data for the first day (c) as a comparison. 
are in a position to test the validity of this by examining the hybrid model run used in section 7. The main measurement of the experiment was based on summing the profits made at each petrol agent each day over the course of the simulations. It was found that maximisation of profit at the local scale did indeed lead to an overall increase in regional profit (Figure 7). This increase was gradual, slowing down as the system reached equilibrium. This suggests that the model is at least capturing potential market behaviour well.

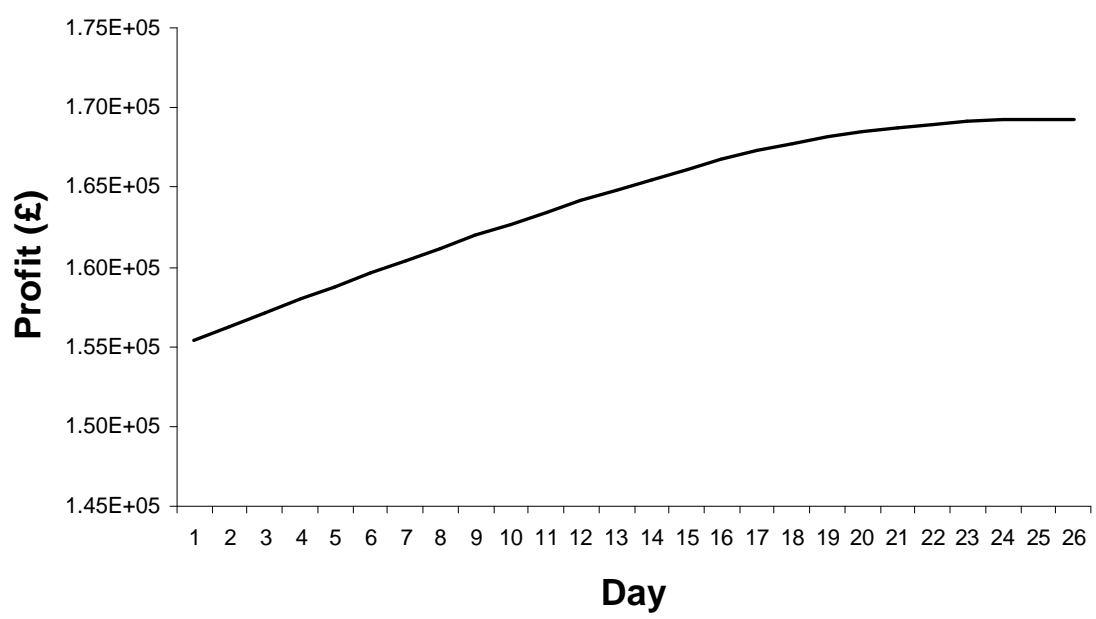

Figure 7: Change in total profit $(\mathfrak{f})$ over the course of the simulation.

\section{Spatial Diffusion of Price Changes}

Experimentation was undertaken with the hybrid model to assess the spatial diffusion of price changes through the system. Idealised conditions were employed to standardise location distribution effects and allow an easier understanding of the patterns produced by the hybrid-model. A grid was constructed over a $20 \mathrm{~km} \mathrm{x} 20 \mathrm{~km}$ area. Petrol stations were located at nodes every $0.5 \mathrm{~km}$. Each square represents a ward (the ward centre is located at the centre of the square) and contains a population of 2000. Every petrol station was assigned the same price (68p) with the centre station set to $63 \mathrm{p}$. It is hypothesised that the cheaper price at the centre station would diffuse through the system at different rates according to the neighbourhood size.

The initial price drop at the centre station was found to gradually spread out to the surrounding area (Figure 8). By the end of the simulation, the price change has diffused out to all of the stations. Figure 9 shows the total price change as a function of distance from the centre station at various times. This illustrates that for a given time there is a relatively sharp interface between the region which has been strongly affected by the price drop and the more distant region where there is only a small drop in price. The rate at which this interfaces propagates through the system is relatively constant with a value of about $0.1 \mathrm{~km}$ per day in this simulation. For distances less than the interface the price change is more or less constant at about $-6.5 \mathrm{p}$. At greater distances the price change slowly drops during the simulation, but in this case never reaches less than about $-3 p$. 


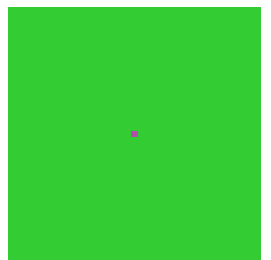

$\mathrm{t}=1$

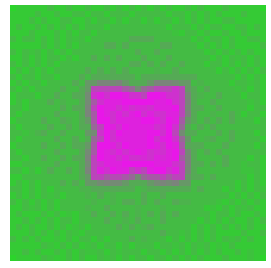

$\mathrm{t}=40$

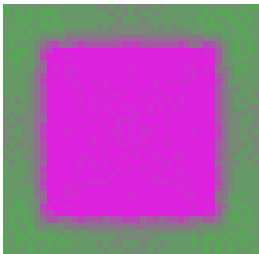

$\mathrm{t}=60$

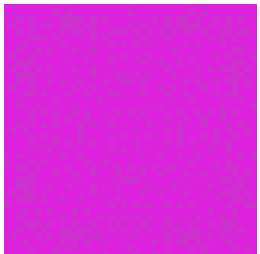

$\mathrm{t}=132$

Figure 8: Spatial diffusion of price changes across the surface at different time (t) stages using a $1 \mathrm{~km}$ neighbourhood.

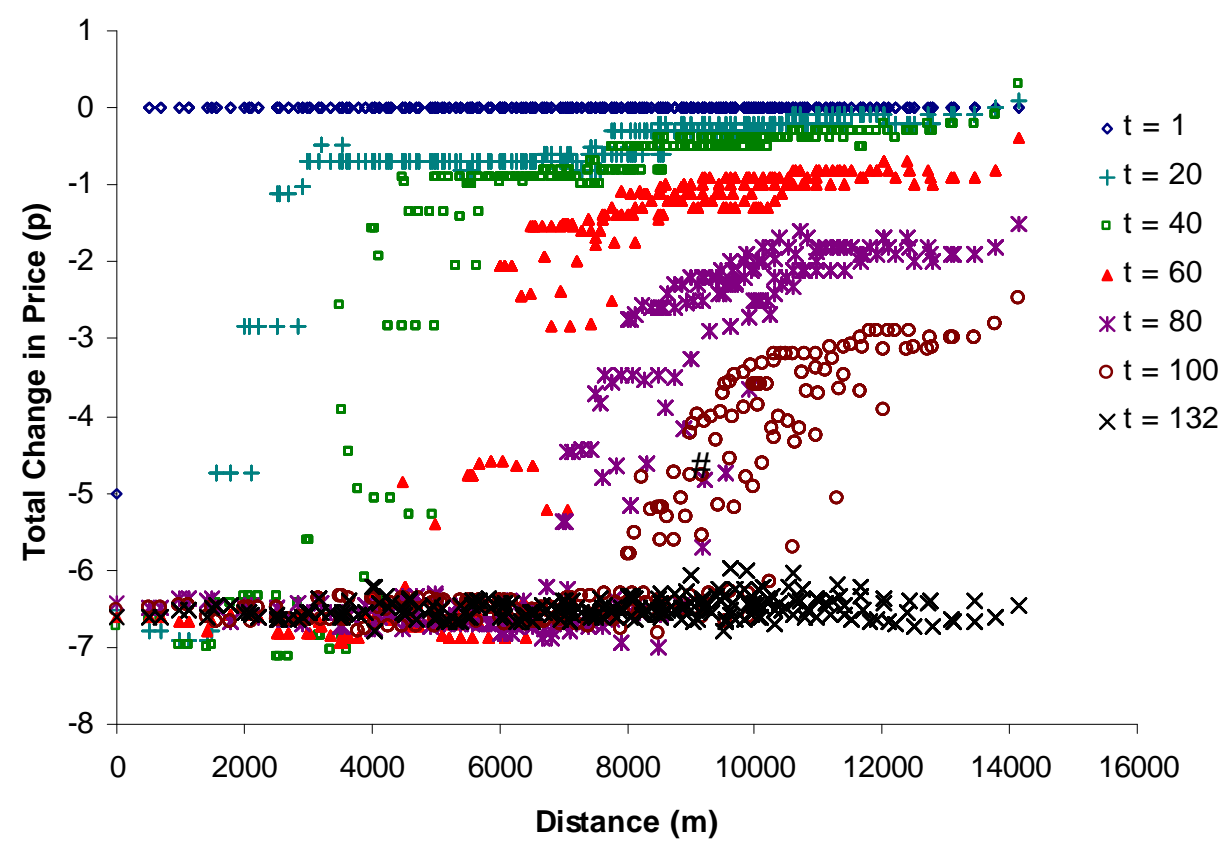

Figure 9: Plot of total price change against distance for various times $(\mathrm{t})$ using a $1 \mathrm{~km}$ neighbourhood to illustrate the propagation of price changes throughout the system.

Varying the size of the neighbourhood had the effect of increasing the rate of dispersion (Figures 10 and 11). The larger the neighbourhood, the faster the price change dispersed. For example, within a neighbourhood of $1 \mathrm{~km}$, the prices diffused out at $0.1 \mathrm{~km}$ per day. With a $5 \mathrm{~km}$ neighbourhood, the rate of diffusion had increased to $0.9 \mathrm{~km}$ per day.

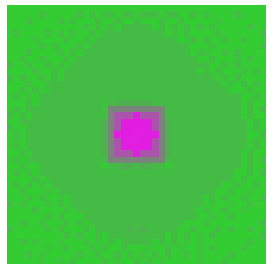

$1 \mathrm{~km}$

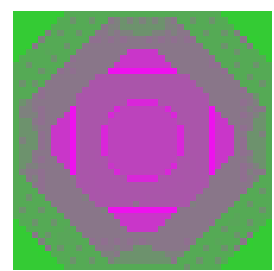

$3 \mathrm{~km}$



$5 \mathrm{~km}$

Diffusion rate $=0.1 \mathrm{~km}$ per day Diffusion rate $=0.5 \mathrm{~km}$ per day $\quad$ Diffusion rate $=0.9 \mathrm{~km}$ per day

Figure 10: Comparison of the spatial diffusion of different neighbourhood sizes at $\mathrm{t}=20$. 




Figure 11: Comparison of the spatial diffusion (and rates) of different neighbourhood sizes at $\mathrm{t}=20$

\section{Conclusions}

In this paper we have demonstrated a hybrid multi-agent model of a petrol market populated by self-interested (profit maximising) agents. This model was found to outperform a multi-agent model that did not account for important system behaviour, for example the movements and patronage of consumers. Despite the good performance of the hybrid model, further experimentation with the assignment of different rules to individual brands is required to reproduce the interactions that occur within real markets. Further experimentation possibilities include temporal variations in external factors, such as crude oil prices.

The hypothesis that local profit maximisation would lead to an overall regional increase in profit was also tested. This was found to be the case with a steady increase in regional profit over time that slowed and levelled off as the system reached equilibrium. This indicated that the hybrid model was accurately capturing potential market behaviour and it was also found that the model reproduced some of the spatial patterns within the real data, for example, the rural-urban divide.

Idealised experiments with a regular distribution of petrol stations and population showed how the prices diffused throughout the system. The rate of diffusion was relatively constant and dependent on the size of the neighbourhood for each of the experiments. The system reached an equilibrium state where there was little variation in price across the stations. 
Multi-agent systems provide an ideal framework in which a retail market can be accurately described. Individual agents (petrol stations) can be successfully supplied with detailed knowledge of the market by the attachment of more specialised models, such as spatial interaction models. This flexibility, coupled with the upsurge in readily available computing power makes agent-based modelling an incredibly valuable tool. This has empowered researchers with the ability to both model complex systems at a finer resolution and to extend theoretical ideas to real world problems.

\section{Acknowledgements}

The work reported within this paper is funded by the ESRC and G-Map. All digitised boundary data are Crown and ED-Line Copyright.

\section{References}

ABHARAT, R.J. and SEE, L., 2000, Comparing Neural Network and Autoregressive Moving Average Techniques for the Provision of Continuous River Flow Forecasts in Two Contrasting Catchments, Hydrological Processes, 14, pp. 2157 - 2172.

BACON, R. W., 1991, Rockets and Feathers; the Asymmetrical Speed of Adjustment of UK Retail Gasoline Prices to Cost Changes, Energy Econ. 1, pp. 211 - 218.

BIRKIN, M., CLARKE, C. and CLARKE, M., 2002, Retail Geography and Intelligent Network Planning. Wiley.

BRENNER, W., ZARNEKOW, R., and WITTIG, H., 1998, Intelligent Software Agents: Foundations and Applications. Springer-Verlag.

CASTANIAS, R. and JOHNSON, H., 1993, Gas Wars: Retail Gasoline Price Fluctuations. The Review of Economics and Statistics, 75, pp. $171-174$.

DEKRUGER, D. and HUNT, B.R., 1994, Image-Processing and Neural Networks for Recognition of Cartographic Area Features, Pattern Recognition, 27(4), pp. 461 483.

DIPLOCK, G. and OPENSHAW, S., 1996, Using simple genetic algorithms to calibrate spatial interaction models. Geographical Analysis, 28:262-279.

ECKERT, A., 2002, Retail Price Cycles and Response Asymmetry. Canadian Journal of Economics, 35, pp. 52 - 77.

ECKERT, A., 2003, Retail Price Cycles and the Presence of Small Firms. International Journal of Industrial Organisation, 21, pp. 151 - 170.

FERBER, J., 1999, Multi-Agent Systems: An Introduction to Distributed Artificial Intelligence. Addison - Wesley.

FISCHER, M.M., 1994, Artificial neural networks: a new approach to modelling interregional telecommunication flows. Journal of Regional Science, 34, pp. 503-527. 
FRANKLIN, S. \& GRAESSER, A., (eds)., 1996, Is it an agent, or just a program? Proceedings Third International Workshop on Agent Theories, Architectures and Languages, Budapest, Hungary, pp. 193 - 206.

GALOETTI, M., LANZA, A. AND MANERA, M., 2003, Rockets and Feathers Revisited: An International Comparison on European Gasoline Markets. Energy Econ, 25, pp. 175 - 190.

GAGARIN, N AND FLOOD, I. AND ALBERT, P., 1994, Computing Truck Attributes with Artificial Neural Networks, Journal of Computing in Civil Engineering, 8(2), pp. $131-148$.

GOODWIN, P. \& WRIGHT G., 1993, Improving judgmental time-series forecasting a review of the guidance provided by research. International Journal of Forecasting, 9(2), pp. 147-161.

JENNINGS, N.R., 2000, On Agent-based software engineering. Artificial Intelligence, 117, pp. $277-296$.

LEK, S. AND GUEGAN, J. F., 1999, Artificial Neural Networks as a tool in Ecological Modelling, an Introduction, Ecological Modelling, 120(2 - 3), pp. 93 102.

MAES, P., 1994, Agents that reduce work and information overload. Communication of the ACM, 37, pp. 68-71.

MANNING, D.N., 1991, Petrol Prices, Oil Price Rises and Oil Price Falls: Evidence for the UK since 1972. Applied Economics, 23, pp. 1535 - 1541.

MITCHELL, J.D., ONG, L.L. and IZAN, H.Y., 2000, Idiosyncrasies in Australian Petrol Price Behaviour: Evidence of Seasonality's. Energy Economics, 28, pp. 243 258.

NOEL, M., 2002, Edgeworth Price Cycles in Retail Gas Markets, PhD Thesis.

NWANA , H.S., 1996, Software Agents: An Overview The Knowledge Engineering Review, 11(3), pp. $205-244$.

O'SUlliVAN, D. AND HAKLAY, D., 2000, Agent-based Models and Individualism: Is the World Agent-Based?, Environment and Planning A, 32(2), pp. $1409-1425$.

PAVE, A., 1994, Modelisation en biologie et en ecologie. Lyon, Aleas.

RECKNAGEL, F., FRENCH, M., HARKONEN, P. AND YABUNAKA, K-I., 1997, Artificial Neural Network Approach for Modelling and Prediction of Algal Blooms, Ecological Modelling 96, pp. 11- 28. 
REILLY, B. and WITT, R., 1998, Petrol Price Asymmetries Revisited. Energy Economics, 20, pp. $297-308$.

SCHELHORN, T., O'SULLIVAN, D. AND HAKLAY, M., 1999, STREETS: An Agent-Based Pedestrian Model, CASA Working Paper 9, University College London, Centre for Advanced Spatial Analysis.

SEE, L. AND OPENSHAW, S., 1997, An introduction to the fuzzy logic modelling of spatial interaction. In: Proceedings of the Joint European Conference and Exhibition on Geographical Information, 16-18 April 1997, Vienna, Austria, IOS Press, pp. 809-818.

SHIN, D., 1994, Do Petrol Prices Respond Symmetrically to Changes in Crude Oil Prices? OPEC Review, 32, pp. 137 - 157.

TORRENS, P. M. AND O'SUlliVAN, D., 2000, Cities, Cells, and Complexity: Developing a Research Agenda for Urban Geocomputation 2000.

TSVETOVAT, M. AND CARLEY, K., 2002, Emergent Specialisation in a Commodity Market: A Multi-Agent Model, Computational and Mathematical Organisation Theory, 8, pp. $221-234$.

WOOLRIDGE, M., 1997, Agent-based Software Engineering, IEE Proc. Software Engineering 144, pp. $26-38$. 